\title{
Construction Project Control Methodologies And Productivity Improvement: EVM, BIM, LBM
}

\author{
Russell Kenley $^{1}$ and Toby Harfield ${ }^{2}$
}

\begin{abstract}
Construction productivity has been and remains a concern of organizations and governments. Productivity is also a concern of individual projects. A recent survey of 50 international construction project controls professionals found limited support for the effectiveness of three well known project control systems: Earned Value Management (EVM), Building Information Modeling (BIM) and Location Based Management (LBM). Analysis of the data collected during semi-structured interviews highlights two important problems in both commercial and infrastructure projects. The study found that all organizations used one or more of these methodologies. However, each of the methodologies was considered effective only for some projects or some parts of those projects. It appears that a major reason for lack of effectiveness is that project team capability and capacity to implement the methodology effectively was variable. However, it may be that an even more important factor is linked to the ineffective implementation; lack of understanding the theory that underpins these types of project control methodologies. EVM, BIM and LBM are all systemic methodologies aimed at reduction of waste as a means to improve productivity, thus all require consistent project process: data collection, monitoring, reporting and forecasting for effective control.
\end{abstract}

Keywords: LBM, BIM, EVM, construction project control professionals.

\section{Introduction}

The purpose of this paper is to assist in the development of project management theory. The report is based on the findings of a sub-set from an exploratory study seeking identification of opportunities for increased systemic project productivity. While the study focuses on project level productivity, construction industry and sector level productivity has long been a focus for governments, industry and academia (Crawford and Vogl, 2006). This interest is because construction is key to sustaining general economic activity in most countries. The call to improve construction industry productivity drives government strategies and targets to reduce the construction costs, because often governments are major clients for infrastructure construction (Kenley, 2014).

However, perceived low levels of industry productivity, according to the research over the last 40 years, is primarily attributed to the uniqueness of projects. The concept of 'uniqueness' is consistently used as the explanation for the variability of both internal and external project inputs for the duration of a project (DelPico, 2013). Thus much construction research has focused on individual projects as one option of improving industry productivity (Rozenes et al., 2006).

\footnotetext{
1 Professor, Swinburne Business School, Swinburne University of Technology, PO Box 218 Hawthorn 3122 Australia, Tel: +61-3-92148000, E-mail: rkenley@swin.edu.au

Visiting Professor, Construction, Unitec Institute of Technology, 139 Carrington Road, Mount Albert, Auckland 1025, New Zealand.

2 Dr, Research Associate, Swinburne Business School, Swinburne University of Technology, PO Box 218 Hawthorn, Victoria 3122, Australia, Tel: +61-3-92148000, E-mail: tharfield@swin.edu.au
} 
Although most elements of the final built environment product (building, road or oil rig) do require unique solutions, over time, standard solutions have been developed that can be applied to many construction management problems. International and nation organizations such as the Project Management Institute and the Australian Institute of Project Management develop guidelines, definitions and methodologies to support the standardization efforts (Ma et al., 2014; Smyth and Morris, 2007).

A significant coordinating feature of standardization is to set out processes that support ways to manage project management variability; in the literature and in practice it is referred to as 'control'. Controlling external and internal uncertainty is considered a major part of any construction project (Eastman et al., 2008) for the implied outcome of improving overall project productivity (Hanna, 2012).

Morris (2014) does not mention productivity in his listing of project management research contributions, but clearly practitioners have an alternative way of understanding the purpose of project control processes. It is to consider them as mechanisms aimed at improving productivity, that is, to limit the negative impact of the uncontrollable factors (Rozenes et al., 2006).

The concept of productivity improvement implies that this improvement is possible through production efficiency, such as completing a project early. Thus a number of tools or methodologies for managing projects have been developed specifically to control internal construction project processes claiming productivity improvement as the outcome (Kenley and Seppänen, 2010; Eastman et al, 2008; Fleming and Koppelman, 2005). The use of these types of project control systems means that it could be possible to increase industry productivity one organization or one project at a time.

However, an important finding of this exploratory interpretive study suggests that the problem of internal project variability that project control tools were meant to mediate, is also a problem that effects implementation of project control tools at the project level. This finding suggests extending project management theoretical applications for a more inclusive understanding of project control practice of commonly used systemic control tools and methodologies.

The balance of this report is organized: the next section concerns the difficulty of defining two concepts; project control and productivity improvement. The research design section has the argument for control to be considered a management skill as a precursor to details of the sample of experts. The next sub-section describes the exploratory interpretative method used to collect the data related to a sub-set of three research questions allied to production efficiency. The third sub-section provides a preliminary analysis of responses from 50 international construction project control professionals to the research questions. The project control section contains a more extensive discussion of three systemic project control mechanisms, BIM, EVM, and LBM. The three methodologies are presented in relation to the research findings and the literature queries, followed by concluding remarks.

\section{Project Control}

One of the major issues in the project control literature is the difficulty of defining control. This comes about because the project management research has a multiplicity of meanings for 'control'. Control is defined as a role, as a process, and as an outcome (Olawale and Sun, 2010). Control is also discussed as a practice, a system and a problem (Isaac and Navon, 2014).

The difficulty of agreeing on a commonly accepted definition may be because of the onerous number of skill-sets needed to measure, monitor, analyze, report and re-schedule projects. Ma et al. (2014) identified five top project manager skills, but control is not on their list. DelPico (2013), on the other hand, writes that control is a fundamental managerial skill 
necessary for all project management roles. Thus, all construction managers need experience and knowledge of the purpose, function and processes of control within projects. This knowledge is embedded in project control tools and methodologies (Rozenes et al, 2006). Therefore, in this report the term 'construction project control professionals' identifies managerial practitioners who all have experience with a range of types of construction projects and project control mechanisms (Leybourne and Sadler-Smith, 2006).

In addition, the dynamic nature of a construction project (Bakry et al, 2014) is best understood from a systems perspective because improvement in productivity requires measures of more than one form of activity. The complex interaction between activities of construction projects involves factors such as work readiness, work flow reliability, materials logistics, etc. (Vanhoucke, 2012). A systems view of productivity implies project management processes aligned to systems-based construction management methodology (Azimi et al., 2012). Arguably the best known is Lean Construction. The fundamental concept of Lean Construction is production efficiency, defined as minimizing waste.

Thus, in this report the concept of control is defined as the application of a systemic project control system. The processes of project control, for the purposes of this report, are connected to the concept of production efficiency (for simplicity sake defined as reduction of waste). And improved project productivity is considered to be the expected outcome of a well implemented project control system (Isaac and Navon, 2014; Azimi et el., 2012; Hanna, 2012; Kenley and Seppänen, 2010; Olawale and Sun, 2010; Crawford and Vogl, 2006; Rozenes et al., 2006)

The definitions for this report must be considered subjective (Creswell, 2014), because during the data collection phase of the exploratory research specific definitions were not used nor requested from the 50 project control professionals who provided data that is the basis of this report. These constraints, should be taken as part of the continuum that is the search for ways and means to improve project productivity as a contribution to project management theory.

\section{Research Design}

The methodology for the explorative study is critical realism (Smyth and Morris, 2007) thus the research report provides descriptive explanations. An interpretative method of data collection and analysis supports the aggregation of the concepts and experiences of project managers as a solution to extensive variations attributed to individuals and organizations (Creswell, 2014; Tuuli et al., 2010). Indeed contributing to project management theory is based on variation inclusion (Smyth and Morris, 2007).

An important part of the research design is the application of the concept of control as a management skill. DelPico (2013, p.7) suggests that "The essence of any type of management is control. It is fundamental to project management; if one is to manage, one must control." If this is case, then all managers, general and specialist, are actually responsible for project control. This reasoning assists with aggregating data variability from the research participants and identifying them as a group of experts (Leybourne and SadlerSmith, 2006) based on their self-reported knowledge of control practices for construction projects. For the purposes of this report 'project control professionals' is an aggregate term established on the understanding of the limitations of categorization (Creswell, 2014).

\section{Three Production Efficiency Research Questions}

If all managers are concerned with control, then it follows that all types of managers working on construction projects will be able to discuss issues of productivity because they are project control professionals. The best way to find out if this is true, is to ask people who are engaged in creating the built environment. 
The answers to these three questions form the basis of this research report:

1. Which one area would you like automated to reduce your workload?

2. Does your organization aim to improve construction production efficiency?

3. What methods does your organization use to improve production efficiency?

Data were collected via personal semi-structured interviews concerning personal and organizational project management processes. The participants were recruited via a snowballing technique based on researcher industry networks. Common work-place and telephone interviews were augmented with opportunistic recruiting at project management conferences and industry meetings (Creswell, 2014) on three different continents and as many islands.

Using an interview based research protocol provided the opportunity for construction project control professionals to discuss productivity issues related to the three questions. All questions were presented with no definitions of productivity, control, efficiency or effectiveness. Expert opinion (Leybourne and Sadler-Smith, 2006), not statistical significance, is the basis of the interpretive research method. Thus, description and implied effects, based on personal meanings developed through years of experience within the construction industry, organizations and construction projects, are self-defined.

This report provides the findings of a sub-set of three questions from a larger study. Three project control methodologies were identified as the most prevalent in a variety of organizations for the purpose of productivity improvement: Building Information Modeling (BIM), Earned Value Management (EVM) and Location-Based Management (LBM).

\section{Research Sample}

Fifty (50) construction project control professionals who work internationally were interviewed. The largest group, $66.0 \%$, identified themselves as project managers (including specialists such as construction or engineering). The next largest group, $24.0 \%$, is made up of planners or schedulers. Five of the sample, are clustered as miscellaneous because only one person in the sample used the identifier: Contracts Manager, Financial Manager, Legal Management, Risk Manager, Business Process Consultant.

Of this experienced group of professionals $56.0 \%$ have been working in the construction industry for more than 20 years and $36.0 \%$ have been in the industry between 11-19 years. Only 4 people have less than 10 years industry experience. The international nature of construction was evident from informal conversations about past projects.

The organizations that these professionals worked for all have capability and capacity to construct across of a spectrum of construction projects. Commercial structures account for construction activities of $78.0 \%$ of organizations. Some common commercial projects are: shopping centers, multi-story car parks, hospitals, schools and residential developments. Of the sample, $42.0 \%$ have experience of infrastructure projects such as: roads, rail, tunnels, and pipelines.

Just as the types of projects vary, so too does the average project value. For $13(26.0 \%)$ of organizations, their projects are in the range of up to $\$ 99 \mathrm{~m}$. The largest organizational group, $21(42.0 \%)$, contract projects valued between $\$ 100 \mathrm{~m}$ and $\$ 999 \mathrm{~m}$. Sixteen $(32.0 \%)$ organizations develop or provide services for projects that are valued at over $\$ 1 \mathrm{~b}$ including a $\$ 56 \mathrm{~b}$ mining complex and a $\$ 120 \mathrm{~b}$ gas $\&$ oil pipeline.

\section{Preliminary Analysis}

A numeral analysis has been used to present a simplistic description (Creswell, 2014) of the variability of the data collected. Analysis of the information collected provides some answers to the three research questions posed above. 


\section{Which one area would reduce your workload if it was automated?}

Nineteen or $38.0 \%$ of the construction project control managers wanted 'monitoring and control' activities automated to reduce their workload. This high number suggests that indeed, managing projects is by definition a project control activity.

On the other hand, years of project management experience means individuals development personal methods of project control. For example; "There is so much adjustment in work scope every year. So it still makes sense to use spreadsheets."

These 19 project managers all worked with one or more of the project control tools listed in Figure 1.

\section{Does your organization aim to improve construction production efficiency?}

All interviewees answered this question. This implies that the entire sample, do indeed have the skills needed for project control. In addition during the interview there was no necessity to suggest a link between production efficiency and the processes of project control methodologies with the implied project productivity improvement outcome. All interviewees understood the implication of the concept.

Forty-two organizations use tools for project control that provide a common set for each project. In some cases the clients provide the tools and in other cases collaborative arrangements for data collection, analysis, reporting and forecasting are made for all or part of the project.

What was surprising that 8 people said that their organizations did not aim to improve efficiency! Only three managers gave reasons why their organizations did not seek to improve efficiency:

- "No, because costs are coming out of their pocket"

- "No, the current system provides what is required"

- "No, not looking due to cost constraints"

\section{What methods does your organization use to improve production efficiency?}

The study found six commonly used productivity methodologies were used by the majority of the organizations as Figure 1 shows. These six were also used on both commercial and infrastructure construction projects. Thirty-nine organizations commonly use two or more systems for project management efficiency.

Twelve organizations also provided information about other types of systems they use. These can be classed as traditional (eg. Gantt Charts or constant review) or digital (eg. IPads). A number of organizations also add specialist software (eg. CrewLoading, Safety Design) to augment their LBM, BIM or EVM control systems.

\section{Project Control Methodologies}

As noted above, all interviewees understood the implication of the concept of the production efficiency link between the processes of project control methodologies and the productivity improvement outcome. Three project control methods developed from a systems perspective are the most commonly used by the organizations in this study. All but nine organizations use at least one of these methodologies: EVM, BIM and LBM. Of that sub-set, $38.1 \%$ use two and $23.8 \%$ use all three for project control.

The claims are that effective implementation of these control methodologies gives rise to improved project productivity outcomes. However, these claims have been questioned by academics as well as some of project control professionals in this study. 


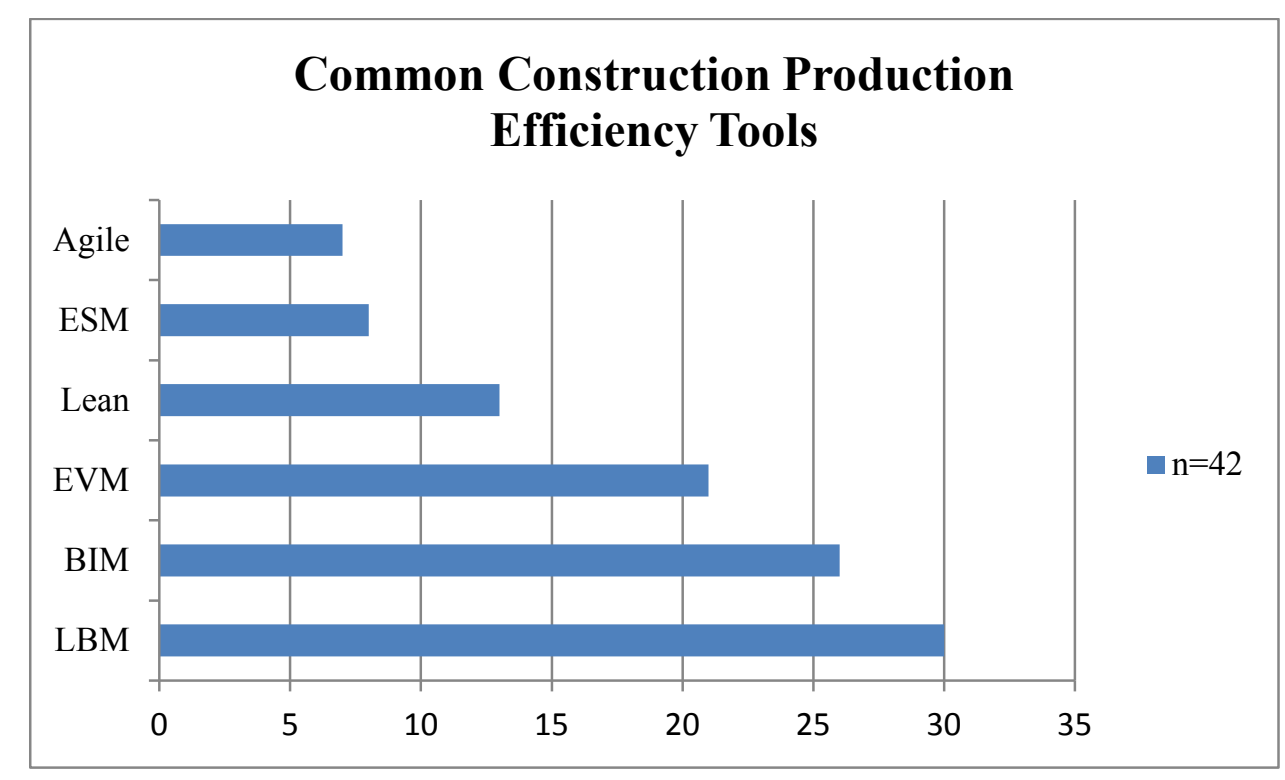

Figure 1. Six Common Construction Production Efficiency Tools

\section{Earned Value Management (EVM)}

Earned Value Management (EVM) is a project management system that monitors cost, schedule and technical performance (Fleming and Koppelman, 2005). The system provides the means to calculate cost and schedule variances. A significant feature is the application of performance indices to forecast project cost and time. In this way progress and performance analysis outcomes indicate corrective action.

Earned value is seen as one way to measure construction output and thus the productivity of the project (Hanna, 2012). A detailed Work Breakdown Structure (WBS) is considered a key part of an Earned Value Management system. The WBS provides the structure necessary to track project progress especially to assign completion to parts of the project. The ability to correctly determine the percentage of completed activities is fundamental for accuracy of the forecasts.

In order to implement an EVM system, data needs to be collected and organized throughout the project. It is therefore understandable that $38.0 \%$ of the construction project control managers in this study wanted 'monitoring and control' activities automated to reduce their workload (Isaac and Navon, 2014).

Because, it takes time and resources to continuously monitor project productivity (Vandevoorde and Vanhoucke, 2006), it has been used as a reason for not focusing on project productivity improvement. However, this was not the case with the construction project control managers in this sample. When asked how many hours per day they spent preparing reports: $22.5 \%$ said between 3 and 10 hours. The majority of the sample, $42.1 \%$ only spent one hour a day and $35.4 \%$ spent two hours daily.

Some controversy exists within the EVM literature concerning the breakdown level that is most appropriate for forecast metrics, at the cost account or higher level or at the level of the activity (Vandevoorde, and Vanhoucke, 2006). Is it best to monitor and control through 'early warnings' at high levels of the WBS, or scheduling adjusted work along the critical path (Galloway, 2006)? These types of basic implementation problems obviously prevent EVM becoming industry standard in the effort to improve industry productivity.

\section{Building Information Modeling (BIM)}

Building Information Modeling (BIM) is a 'set of interacting policies, processes and technologies that generates a methodology to manage' all the essential design and project 
information of construction projects (Lee et al., 2014, p.65). This is possible because of the global effort to create the necessary open standards, processes and definitions (http://www.buildingsmart-tech.org/). These all support a real-time evaluation of productivity gains when using BIM to transfer and collect construction project information (Lu et al., 2014). While, the jury is still out on the overall benefits for individual projects, one of the main reasons that governments and AEC professionals argue for BIM platformed projects, is the obvious benefit of the use of 3D models (Eastman et al., 2008). Building objects used for design enables 'clash detection' or 'design resolution' for commercial projects. Productivity gains are possible if less waste caused by rework is prevented by the use of these BIM features (Eastman et al, 2008; Björnfot and Jongeling, 2007).

As the interoperability issues of BIM are addressed (Amor and Dimyadi, 2010), it can be assumed that support for BIM will continue to grow. Almost all of the organizations (42 out of 50) or $84.0 \%$ in our study use BIM to improve production efficiency for all or part of both commercial and infrastructure construction projects.

At the same time, organizations that use BIM, do not use BIM on all projects due to issues of both capacity and capability of all types of resources. Therefore it is not surprising that when asked "if BIM was effective on projects or for design resolution?", a variety of general and specific instances were described. However, over all, the assessment of the project control professionals in this study is not positive:

- "BIM is effective for project administration"

- "BIM is effective, but only on some projects"

- "BIM works reasonably well, but still only $50 \%$ effective on site"

Clearly, as a total system for project control, BIM is still a work in progress. However, the concern with productivity at the industry level suggests that continuing research into appropriate application of BIM at the project level will lead to growth of both capability and capacity within the industry (Lee et al, 2014; Lu et al., 2014).

\section{Location Based Management (LBM)}

Location is the one characteristic that differentiates construction projects from other types of projects. Location is a major feature of each built environment structure: bridges, roads, rail lines, high-rises or wide-rise buildings.

All construction projects are 'location-oriented', with location being both implicit and explicit for all construction management endeavors. Indeed, Ibrahim et al. (2009) found that 'location' is a principle criterion used by Project Management practitioners for the design and decomposition of work breakdown structures for construction projects.

So it comes as no surprise that over half of the organizations, $52.0 \%$, use Location Based Management (LBM) for project control. Location as the unit of analysis is at the heart of the LBM. Location enables all building data to be allocated to a data container that has meaning during construction. Effectively, location-based data allows performance to be reported at the level of location (eg. a room, zone, floor or chainage) for many functions, including cost, quality and time throughout a project. This provides precision in planning and progress reporting or control (Kenley and Seppänen, 2010).

For example, with location-based scheduling, 'task' is the unit of control. In this way, the information about a task may be described once, then used in a hierarchy of locations. This type of location breakdown structure (LBS) can be used to replicate information efficiently (Kenley, 2004), eliminating waste and improving project management productivity. 
Of the identified project schedulers in the study, $75.0 \%$ work for organizations that use LBM for productivity improvement. At the same time only 13 project control professionals provide a positive evaluation of the effectiveness of LBM. The low positive response rate is definitely of concern. When asked if LBM was effective for project control, this reply suggests a problem with implementation: "Not at the workface, only $10 \%$ effective."

Developers of project control methodologies would argue that effective application of their tools must be based on the underlying systems perspective. Applying LBM as if a construction project was static rather than dynamic would probably result in it being considered "only $10 \%$ effective".

However, another response indicates a more fundamental problem, "LBM is not effective" because, the people using it "are not following the location philosophy". This statement appears to capture implementation issues related to all project control systems developed from systems theory (Morris, 2010). If this is the case, then such project control tools will not become industry standard without significant capability and capacity building.

\section{Conclusions}

The purpose of this paper is to assist in the development of project management theory based on the findings of a sub-set of the larger study that is part of the search for ways and means to improve systemic project productivity. Project control is considered to be a necessary skill for all types of construction manager: project managers, contract managers, engineering managers and of course control managers. Fifty international construction project control professionals provided data for this exploratory interpretative study that focuses is on practice-related responses to three common project control methodologies.

Control has been identified as a contributing factor for project success. The project management literature is replete with models promising control of cost and duration, process models for more effective project delivery and software to support these research findings. However, consistent construction project control still remains elusive.

Controlling external and internal uncertainty is considered a major part of any construction project for the implied outcome of improving overall project productivity. According to the project control professionals interviewed, the majority of the organizations they work for are concerned with improving the project productivity. This is evident by current projects using one or more of three common systemic control mechanisms: Earned Value Management (EVM), Building Information Modeling (BIM), and Location-Based Management (LBM). However, the opinion of the majority of the very experienced managers is a lack of total effectiveness for each of these methodologies.

In other words, the problem of internal project variability that these project control tools are meant to mediate is also a problem that effects the implementation of these three common project control tools. Clearly the use of these tools requires additional capacity and capability to ensure project data collection, reporting, forecasting and re-scheduling to produce improved productivity.

This however, requires more than just up-skilling both within organizations and the industry. It also requires providing these skills based on a clear understanding of the under lying philosophy related the assumption that project productivity improvement (waste reduction and mitigation of variation) is the expected outcome of the process of project control.

\section{Acknowledgment}

This paper has been developed with funding and support provided by Australia's Sustainable Built Environment National Research Centre (SBEnrc) Project 2.21. Core Partners in 2015: Government of Western Australia, NSW Roads \& Maritime Services, Queensland Transport 
\& Main Roads, John Holland Group, Aurecon, Swinburne University of Technology, Curtin University of Technology and Griffith University of Technology.

\section{References}

Amor, R. and Dimyadi, J., 2010. An open repository of IFC data models and analyses to support interoperability deployment. In: Proceedings of the CIB W78 $27^{\text {th }}$ international conference, 16-18 November 2010, Cairo, Egypt, 10pp.

Azimi, R.; Lee, S.H. and AbouRizk, S.M., 2012. Applying basic control theory principles to project control: case study of off-site construction shops. Journal of computing in civil engineering, 26(6), 681-690.

Bakry, I., Moselhi, O. and Zayed, T., 2014. Optimized acceleration of repetitive construction projects. Automation in construction, 39, 145-151.

Björnfot A. and Jongeling, R., 2007. Application of line-of-balance and 4D CAD for lean planning. Construction innovation, 7(2), 200-211.

Crawford, P. and Vogl, B., 2006. Measuring productivity in the construction industry. Building research information, 34(3), 208-219.

Creswell, J.W., 2014. Research design: qualitative, quantitative, and mixed method approaches, $4^{\text {th }}$ edition, Los Angeles: Sage.

DelPico, W.J., 2013. The basics in project control: integrating cost and schedule in construction. Hoboken, NJ: John Wiley \& Sons Online Books. DOI: 10.1002/9781118802717.

Eastman, C., Teicholz, P., Sacks, R. and Liston, K., 2008. BIM handbook: A guide to building information modeling for owners, managers, designers, engineers and contractors, New Jersey, US: Wiley \& Sons.

Fleming, Q.W. and Koppelman, J.M., 2010. Earned value project management, $4^{\text {th }}$ edition. Newtowns Square, PA: Project Management Institute.

Galloway, P.D., 2006. Scheduling for construction projects survey of the construction industry relative to the use of CPM scheduling for construction projects. Journal of construction engineering and management, 132(7), 697-711.

Hanna, A.S., 2012. Using the Earned Value Management System to improve electrical project control. Journal of construction engineering and management, 138(3), 449-457.

Ibrahim, Y.M., Kaka, A., Aouad, G. and Kagioglou, M., 2009. Framework for a generic work breakdown structure for building projects. Construction innovation: information, process, management, 9(4), 388-405.

Isaac, S. and Navon, R., 2014. Can project monitoring and control be fully automated? Construction management and economics, 32(6), 495-505.

Kenley, R., 2014. Productivity improvement in the construction process. Construction management and economics, 32(6), 489-494.

Kenley, R., 2004. Project micromanagement: practical site planning and management of work flow. In: Proceedings of the international group for learn construction conference, 03-05 August 2004, Copenhagen, Denmark, 194-205.

Kenley, R. and Seppänen, O., 2010. Location-based management for construction: planning, scheduling and control. Abingdon: Spon Press.

Lee, N., Salama, T. and Wang, G., 2014. Building information modeling for quality management in infrastructure construction projects [online]. Available from: http://itc.scix.net/data/works/att/w78-2014-paper-009.pdf [Accessed 15 April 2015].

Leybourne, S. and Sadler-Smith, E., 2006. The role of intuition and improvisation in project management. International journal of project management, 24(6), 483-492.

Lu, W., Fung, A., Peng, Y., Liang, C. and Rowlinson, S., 2014. Cost-benefit analysis of building information modeling implementation in building projects through 
demystification of time-effort distribution curves. Building and environment, 82, 317 327.

Ma, T., Luong, C. and Zuo, J., 2014. A study of the skills of construction project managers in Australia and their needs for training and certification. In: Proceedings of 2014 EPPM conference, 26-28 November 2014, Port Elizabeth, SA. Available from: http://www.ppml.url.tw/EPPM/conferences/2014/papers.htm [Accessed 15 May 2015].

Morris, P.W.G., 2010. Research and the future of project management. International journal of managing projects in business, 3(1), 139-146.

Olawale, Y. and Sun, M., 2010. Construction project control in the UK: existing problems and recommendations for future improvement. International journal of project management, 33(3), 623-637.

Olawale, Y. and Sun, M., 2013. PCIM: project control and inhibiting-factors management model. Journal of management in engineering, 29(1), 60-70.

Rozenes, S., Vitner, G. and Spraggett, S., 2006. Project control: literature review. Project management journal, September, 5-14.

Smyth, H.J. and Morris, P.W.G., 2007. An epistemological evaluation of research into projects and their management: methodological issues. International journal of project management, 25(4), 423-436.

Tuuli, M.M., Rowlinson, S. and Koh, T.Y., 2010. Control modes and mechanisms in construction project teams: drivers and consequences. Construction management and economics, 28(5), 451-465.

Vandevoorde, S. and Vanhoucke, M., 2006. A comparison of different project duration forecasting methods using earned value metrics. International journal of project management, 24(4), 289-302.

Vanhoucke, M., 2012. Measuring the efficiency of project control using fictitious and empirical project data. International journal of project management, 30(2), 252-263. 